\title{
What separates them from us?
}

\section{BOOK TITLE:}

Elephant sense and sensibility: Behavior and cognition

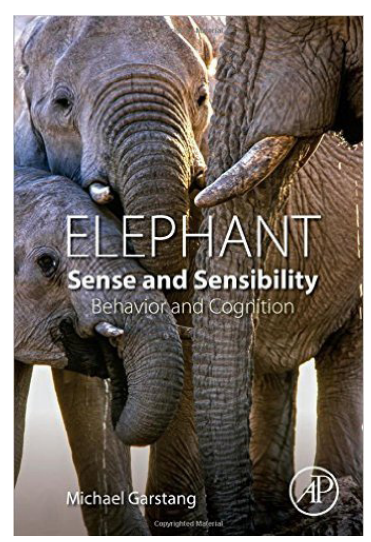

AUTHOR:

Michael Garstang

ISBN:

9780128022177 (softcover)

\section{PUBLISHER:}

Academic Press, London; USD42.46

\section{PUBLISHED:}

2015

\section{REVIEWER:}

Rob Slotow

\section{EMAIL:}

slotow@ukzn.ac.za

\section{AFFILIATION:}

Amarula Elephant Research Programme, School of Life Sciences, University of KwaZuluNatal, Durban, South Africa

\section{POSTAL ADDRESS:}

DVC Suite, 1st Floor Desmond Clarence Building, Howard College campus, University of KwaZulu-Natal, Durban 4041, South Africa

\section{HOW TO CITE:}

Slotow R. What separates them from us? S Afr J Sci. 2016;112(1/2), Art. \#a0140, 2 pages. http://dx.doi. org/10.17159/sajs.2016/a0140

(c) 2016. The Author(s). Published under a Creative Commons Attribution Licence.
Michael Garstang has provided us with a short treatment of elephant behaviour and cognition, which sets out to place aspects of elephant behaviour, psychology, and cognition into a biological context. It is certainly a challenging task, given that we actually know surprisingly little on this subject, and that there are major risks of anthropomorphising interpretations in this context. This risk is emphasised by the author in the introduction, in which he points out that 'while we are able to consider significant findings, these will not be without contention, not in many cases fully supported by definitive scientific evidence'. His approach is to explore the subject by describing both his own observations (he has studied sound communication in elephants extensively) as well as drawing on those from colleagues and the literature, and to then place these observations into a theoretical framing. In his own words 'we draw upon unverified anecdotal evidence not as proof of concept but as possible guidance to the development of a testable hypothesis or the formulation of a question'.

The book is relatively short, about 120 pages, and is structured into 14 (short) chapters, starting with a phylogenetic contextualisation followed by a description of the elephant brain and neural function. Garstang then proceeds with four chapters that deal with memory, morality, emotions, and empathy and altruism, largely, in his words 'in our attempt to penetrate the mind of an elephant'. These chapters are then followed by four chapters that deal with communication, language, intelligence, and teaching and learning. He finishes with a concluding chapter entitled 'Them and Us', which examines elephant conservation, management, and especially human conflict with elephants, including that through poaching.

The approach of the author is to develop a moral position about elephants as a species, and he poses the question at the start of Chapter 14 as 'at this point in our effort to penetrate an elephant's mind we need to ask what have we learned about an elephant's mind and what separates them from us?' As he moves through the various chapters, he continually references what he is saying about elephants back to human context, and he concludes on p. 104 that: 'Elephants are sentient beings differing from humans only in degree and not kind.' He indicates that this conclusion 'requires that we re-examine the relationship between ourselves and elephants' and poses the question of 'what sets us apart and what justifies the acceptance of significantly different privileges for one species versus another?'.

Throughout the book it is clear that the author has a particular agenda, to demonstrate that elephants are not that different from people, and that we have a moral obligation to treat them with due respect and concern, especially in the context of protecting them for persistence. Does this make the book one-sided, of lesser value, or of lesser interest? At the start of the review, I highlighted the challenge of anthropomorphising animals, and my review so far should emphasise to the reader that the author treads a delicate line throughout the book, the line of is it science or pseudoscience?

I have been deliberate in this review in laying out the challenge, and the reader may interpret that I do not believe that the book has value, or that the book is not worth reading. I have been deliberate in creating this context, but I now want to approach the assessment differently. One of the key issues that we have been tussling with in the conservation community in South Africa, and more broadly, is how we treat animals from a welfare perspective. This issue has been forefront in the debates on management of elephants in South Africa, and a very important context for conservation has emerged. As part of the process undertaken by the Department of Environmental Affairs and Tourism of developing norms and standards for the management of elephants ${ }^{1}$, all the aspects that are dealt with by Garstang were taken into consideration. A conclusion was reached that elephants are not simply like other animals. The norms and standards ${ }^{1}$ articulate this conclusion in the following way: Clause 2(a)(vii) 'recognises their sentient nature, highly organised social structure and ability to communicate'; Clause 3(a), 'elephants are intelligent, have strong family bonds and operate within highly socialised groups and unnecessary disruption of these groups by human intervention should be minimised'; and Clause 3(h), 'management interventions must, wherever practicable, be based on scientific knowledge or management experience regarding elephant populations and must (i) take into account the social structure of elephants and (ii) be based on measures to avoid stress and disturbance to elephants'. In the summary for policymakers from the Assessment of South African Elephant Management, the authors point out that elephants exhibit characteristics 'in combination, and to such a degree, that people of many different cultures and backgrounds agree that elephants must be managed with a degree of respect greater than that afforded to most other species of wild animals'2(p.SPM3). It is because of this recognition that elephants are managed within South Africa in a manner that is compatible with their complex psychology, which requires that we approach elephant management from an elevated status of welfare concerns.

While this was the sentiment expressed in the process and outcomes of the norms and standards in South Africa, and is dealt with in various chapters of the Assessment summarised above, it is very difficult to access a readable integration on which this sentiment is based. I see this as the main value of the book by Garstang. What he has done, is to systematically work through our understanding of elephant biology and psychology so that we develop an understanding that elephants are not simply other animals. An understanding that there is complexity and depth to elephants which reflects strongly our own biology, which has evolved from being a social, long-lived species with overlapping generations that have enabled evolution of cultural attributes such as language, and corresponding neurological development. The arguments he puts forward are a mixture of very little scientific evidence, anecdotes, observations, and conjecture, especially in creating parallels with humans. While there are challenges with this approach, to his credit he emphasises these upfront, and, I believe, does a credible job of pulling it all together. I believe that he will convince readers that elephants are indeed complex social species, which are different from other animals. The challenge will be whether he has convinced the reader strongly enough for us to change our collective moral viewpoint to recognise them as sentient, and different from us only in degree, and requiring an 
assessment of the 'privileges' we accord them. Notwithstanding this, I do need to point out that the book is not comprehensively referenced, and that the author does not make enough reference to the various chapters in the Assessment, especially the one on ethics by Lötter et al. ${ }^{3}$

While many readers may find the book challenging in that it skirts, and sometimes crosses into, anthropomorphising, the book does a very good job of putting pieces of a puzzle together that enables us to understand that elephants are different from other animals, and maybe not that different from humans. Because the book is short, and because he makes the 'evidence' accessible, the book is an easy read. I believe that it provides an excellent resource for making us think more about what we are and what we do. This makes the book an important read for conservation practitioners, not only in South Africa, for undergraduate and postgraduate students who are developing their world view, and for academics who may be set in their ways, as a means to think outside the box. For anyone who wants to form and express views on how we should manage and engage with other species, the book provides a reference point, underpinned by substantive, if passionate, argument, for a particular perspective; a perspective, I believe, that needs to be incorporated into the debate we should continually be having around conservation practice and management.

\section{References}

1. Department of Environmental Affairs and Tourism. National norms and standards for the management of elephants in South Africa, in terms of the National Environmental Management: Biodiversity Act, 2004 (Act No. 10 of 2004). Government Gazette No. 30833, 29 February 2008, South Africa.

2. Scholes RJ, Carruthers J, Van Aarde R, Kerley GIH, Twine W, Grobler DG, et al. Summary for policymakers: Elephant management in South Africa. In: Scholes RJ, Mennell KG, editors. Assessment of South African elephant management. Johannesburg: Wits University Press; 2008. p. SPM1-20.

3. Lötter HPP, Henley M, Fakir S, Pickover M, Ramose M. Ethical considerations in elephant management. In: Scholes RJ, Mennell KG, editors. Assessment of South African elephant management. Johannesburg: Wits University Press; 2008. p. 307-338. 